\title{
Global burden of medication non-adherence in chronic obstructive pulmonary disease (COPD) and asthma: a narrative review of the clinical and economic case for smart inhalers
}

\author{
Evalyne M. Jansen ${ }^{1}$, Susanne J. van de $\mathrm{Hei}^{2,3} \wedge$, Boudewijn J. H. Dierick ${ }^{1,3,4}$, Huib A. M. Kerstjens ${ }^{3,5,6}$, \\ Janwillem W. H. Kocks ${ }^{3,6,7,8}$, Job F. M. van Boven ${ }^{1,3,6 \wedge}$
}

${ }^{1}$ Department of Clinical Pharmacy \& Pharmacology, University Medical Center Groningen, University of Groningen, Groningen, The Netherlands; ${ }^{2}$ Department of Health Sciences, University Medical Center Groningen, University of Groningen, Groningen, The Netherlands; ${ }^{3}$ Groningen Research Institute for Asthma and COPD (GRIAC), Groningen, The Netherlands; ${ }^{4}$ Department of General Practice \& Elderly Care Medicine, University Medical Center Groningen, University of Groningen, Groningen, The Netherlands; ${ }^{5}$ Department of Pulmonary Diseases and Tuberculosis, University Medical Center Groningen, University of Groningen, Groningen, The Netherlands; ${ }^{6}$ Medication Adherence Expertise Center of the northern Netherlands (MAECON), Groningen, The Netherlands; ${ }^{7}$ General Practitioners Research Institute (GPRI), Groningen, The Netherlands; ${ }^{8}$ Observational and Pragmatic Research Institute (OPRI), Singapore

Contributions: (I) Conception and design: All authors; (II) Administrative support: None; (III) Provision of study materials or patients: None; (IV) Collection and assembly of data: None; (V) Data analysis and interpretation: None; (VI) Manuscript writing: All authors; (VII) Final approval of manuscript: All authors.

Correspondence to: dr. Job F. M. van Boven. University Medical Center Groningen, Hanzeplein 1 (Internal postcode EB70), 9700 RB Groningen, The Netherlands. Email: j.f.m.van.boven@rug.nl.

\begin{abstract}
Medication non-adherence to asthma and chronic obstructive pulmonary disease therapy poses a significant burden for patients and societies. Non-adherence encompasses poor initiation, implementation (including poor inhalation technique) and non-persistence. Globally, non-adherence is associated with poor clinical outcomes, reduced quality of life and high healthcare and societal costs. Costs are mainly caused by excess hospitalizations and impaired work productivity. Multiple intervention programs to increase adherence in patients with asthma and chronic obstructive pulmonary disease have been conducted. However, these intervention programs are generally not as effective as intended. Additionally, adherence outcomes are mostly examined with non-objective or non-granular measures (e.g., self-report, dose count, pharmacy records). Recently developed smart inhalers could be the key to objectively diagnose and manage non-adherence effectively in patients with asthma and chronic obstructive pulmonary disease. Smart inhalers register usage of the inhaler, record time and date, send reminders, give feedback about adherence and some are able to assess inhaler technique and predict exacerbations. Still, some limitations need to be overcome before smart inhalers can be incorporated in usual care. For example, their cost-effectiveness and budget impact need to be examined. It is likely that smart inhalers are particularly cost-effective in specific asthma and chronic obstructive pulmonary disease subgroups, including patients with asthma eligible for additional GINA-5 therapy (oral corticosteroids or biologics), patients with severe asthma in GINA-5, patients with asthma with shortacting beta2 agonists overuse, patients with asthma and chronic obstructive pulmonary disease with frequent exacerbations and patients with asthma and chronic obstructive pulmonary disease of working-age. While there is high potential and evidence is accumulating, a final push seems needed to cost-effectively integrate smart inhalers in the daily management of patients with asthma and chronic obstructive pulmonary disease.
\end{abstract}

Keywords: Asthma; chronic obstructive pulmonary disease (COPD); smart inhaler; (non)-adherence; costeffectiveness; clinical outcomes

Submitted Jul 03, 2020. Accepted for publication Jan 18, 2021.

doi: $10.21037 /$ jtd-20-2360

View this article at: http://dx.doi.org/10.21037/jtd-20-2360

^ ORCID: Susanne J. van de Hei, 0000-0003-2844-6904; Boudewijn J. H. Dierick, 0000-0001-6524-4290; Huib A. M. Kerstjens, 00000001-7705-7927; Janwillem W. H. Kocks, 0000-0002-2760-0693; Job F. M. van Boven, 0000-0003-2368-2262. 


\section{Introduction}

Worldwide, respiratory diseases are one of the leading causes of death, of which chronic obstructive pulmonary disease (COPD) and asthma are most common. In 2015, 174 million and 358 million people suffered from COPD and asthma worldwide of which 3.2 and 0.4 million die each year, respectively (1). Besides the high healthcare burden, asthma and COPD also cause high economic burden both consisting of direct healthcare costs and indirect costs such as work productivity losses (2-4).

To help achieving asthma and COPD treatment goals, i.e., preventing exacerbations and increase patients' quality of life, both pharmacological and non-pharmacological treatments are available. Non-pharmacological treatments include increasing physical activity, smoking cessation and improved nutrition, whereas pharmacological treatment mainly consists of bronchodilators and anti-inflammatory drugs. These drugs have demonstrated beneficial effects in randomized controlled trials $(5,6)$. Yet in daily realworld practice, effects are often less profound due to nonadherence. Indeed, around $22-78 \%$ of patients with asthma and COPD are poorly adherent to their medication (7). This high non-adherence rate has multiple causes, among which that patients do not start their medication, that they do not use the medication as intended, or that they are not persistent to therapy (8). It is suggested that an increase in adherence could improve clinical outcomes and quality of life of patients and decrease the economic burden of asthma and COPD $(3,9)$. Therefore, physicians, pharmacists and nurses should pay proper attention to the optimal management of non-adherence.

Notably, in the past fifteen years, electronic monitoring devices (EMDs) or so called "smart inhalers" have been introduced, which can monitor adherence objectively, and provide patients with feedback regarding adherence and inhalation technique (10-12). Therefore, smart inhalers seem a promising addition to our therapeutic patient management arsenal. However, the clinical and economic consequences of implementing these devices are still unclear and subject to debate. The aim of this review is to provide a narrative overview of both the extent of medication nonadherence, its clinical and economic consequences as well as potential solutions, with a focus on the recently developed smart inhalers.

We present the following article/case in accordance with the Narrative Review reporting checklist (available at http:// dx.doi.org/10.21037/jtd-20-2360).

\section{Methods}

This narrative review was informed by a semi-structured search in PubMed for English language articles, performed in May 2020, and with key terms being "medication adherence", "asthma", and "COPD" (including their synonyms), without any date of publication restrictions.

\section{Narrative}

\section{Global epidemiology and burden of medication adherence in patients with asthma and COPD}

Adherence to therapy can be defined as "the extent to which a person's behavior corresponds with the agreed recommendations from a healthcare provider" (13). Although it is recommended to be adherent to therapy, many patients tend to forget their medication, either intentionally or unintentionally $(11,14)$. Globally, asthma and COPD adherence rates are generally very poor. For example, patients with COPD have an adherence rate of only $22 \%$ in South-Korea, $29.2 \%$ in China, $34.8 \%$ in Italy, 23.9\% in Belgium, 32.4\% in Spain, 25\% in Canada, 23.4\% in the United States (US) and $27.4 \%$ in Nigeria (Figure 1) (9,15-21). Except for Brazil and Italy, with an adherence rate of $52 \%$ and $43.8 \%$ among patients with asthma, respectively, the adherence rate of patients with asthma is not much better: patients with asthma in US are for $22.2 \%$ adherent, in France for $24.9 \%$, in Ethiopia for $18 \%$, in Saudi-Arabia for $27.4 \%$, in China for $13.8 \%$, in Australia for $19.4 \%$ and in New-Zealand for only $30 \%$ (Figure 1) (22-30). While true differences in patient adherence between countries could actually exist, it should be acknowledged that also the definitions of adherence or the adherence measurement methods contribute to variation.

\section{Taxonomy of adberence and its phenotypes}

The adherence process (or: patient journey) comprises three chronological phases which are categorized according to the ABC taxonomy: (A) initiation, (B) implementation and $(C)$ persistence (8). The initiation is a binary variable: a patient either starts taking their medication or does not. Implementation is whether the actual dosing of the patient corresponds with the prescribed dosing regimen (e.g., inhalation technique, frequency and correct dose). Lastly, the persistence is the time from initiation of the treatment to discontinuation of the therapy (8). Both in asthma and COPD, inhaler devices are most commonly used to deliver 


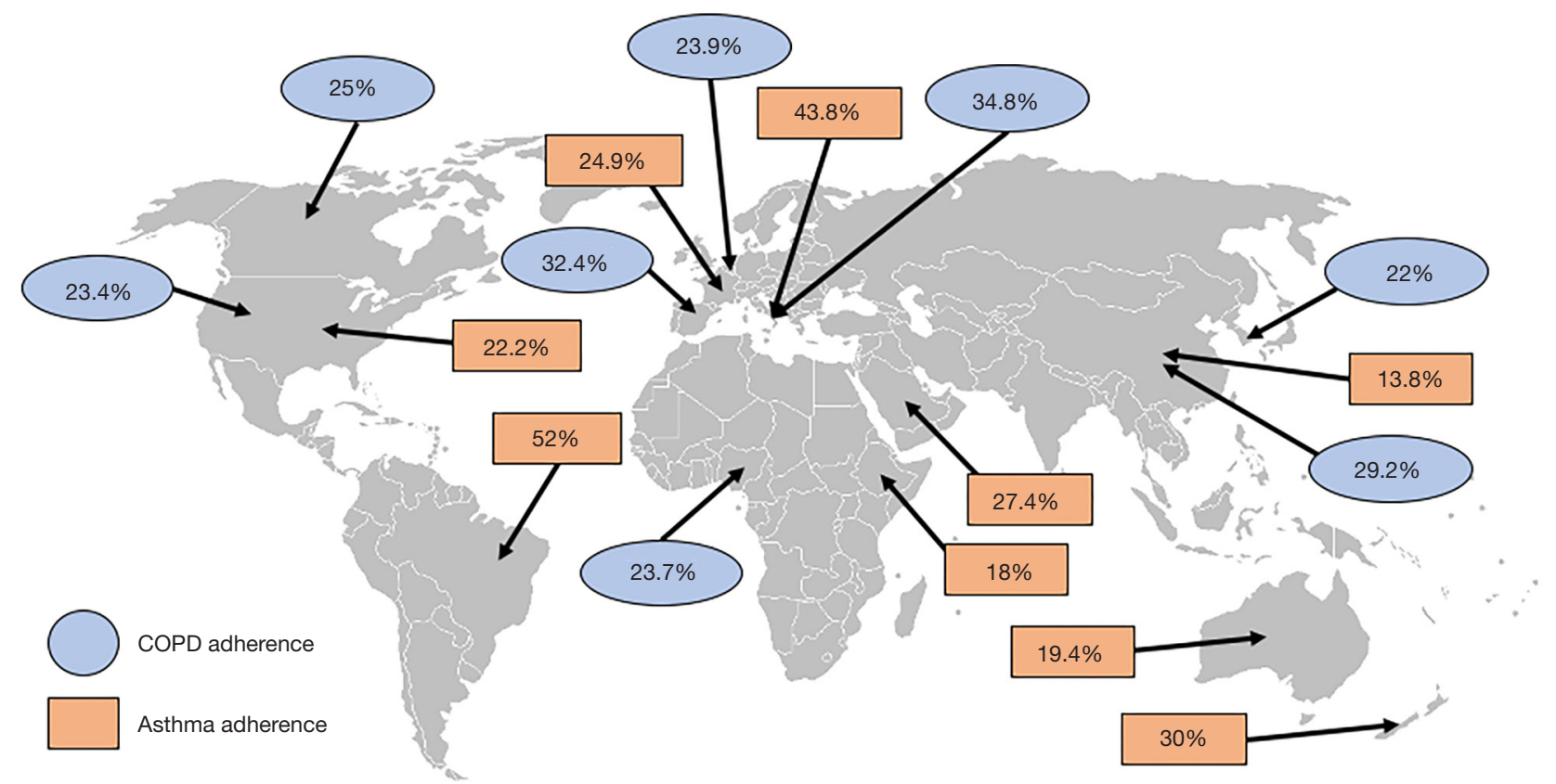

Figure 1 Medication adherence rates across the globe for patients with asthma/COPD. The blue circles represent COPD adherence in the following countries: South Korea, China, Italy, Belgium, Spain, Nigeria, the US and Canada. The orange blocks represent asthma adherence in the following countries: New Zealand, Australia, China, Ethiopia, Saudi Arabia, Brazil, the United States, France and Italy. COPD, chronic obstructive pulmonary disease.

medication to the lungs. Therefore, the proper use of the inhaler is of prime importance. There is a difference between not using the inhaler and the incorrect use of the inhaler. The first can be intentional or unintentional; the latter is usually unintentional, patients do inhale their medication, but not correctly (11). Research shows that only $18.2 \%$ of the patients with asthma was able to perform more than seven of the eleven inhalation steps correctly (24). For patients with COPD, only $6 \%$ was able to fulfil the correct inhaler technique and to use their inhaler regularly over $80 \%$ of the time (11).

Besides the ABC taxonomy, which focusses on the chronological phases of adherence, adherence can also be grouped by underlying behavior. These behavioral forms (or phenotypes) of adherence are described by the World Health Organization (WHO) and have an impact on all chronological phases of the ABC taxonomy. These types are referred to as erratic, unwitting or intelligent nonadherence (13). "Erratic non-adherence" is most wellknown and is mainly caused by forgetfulness, e.g., due to a disorganized or busy lifestyle. Patients who do not understand or unintentionally misapply the medication instructions, suffer from "unwitting non-adherence". In asthma/COPD, this includes not understanding the regimen (e.g., once $v s$. twice daily) or a poor inhaler technique. Lastly, "intelligent non-adherence" is the deliberate, intentional, choice of patients to not take their medication as prescribed (13). This could have different underlying reasons including the fear of side-effects, not feeling sick or high costs.

\section{Effect inhalation technique on adberence astbma and COPD}

Inhalation technique affects adherence via the second phase of adherence: implementation. The most frequently occurring inhalation errors are an insufficient inspiratory flow, not exhaling before inhaling the medication, absence of breath hold after inhaling the medication and unsuccessful dose preparation $(8,24,31)$. Up to $94 \%$ of the dry powder inhaler (DPI) users, both patients with asthma/COPD, make at least one inhaler error during each inhalation that results in suboptimal treatment $(3,32)$. The CRITical Inhaler mistaKes and Asthma control 
(CRITIKAL) study showed that approximately $35 \%$ and $47 \%$ of the patients with asthma using a DPI or metered dose inhaler (MDI) respectively, had an insufficient inspiratory flow (33). An Italian real-world study showed that switching inhaler devices led to inhalation errors due to the fact that the patients had to learn to deal with another device (34). However, when patients switched to inhaler devices which were engineered to minimize inhaler errors significantly less inhalation errors occurred (35).

\section{How to determine adherence in patients with asthma or COPD?}

There are different methods to determine adherence in patients with asthma or COPD. For example, the initiation of treatment is measured by examining whether medication is prescribed and consequently collected/dispensed at the pharmacy (8). This method has its limitations, because dispensing data does not prove whether a patient actually starts using the medication (11).

The same holds true for one of the most commonly used methods, i.e., patients' self-reported adherence, that usually underestimates true rates of non-adherence (i.e., overestimates the rates of adherence), due to socially desired answers (36). While self-report is of less value to measure the extent of non-adherence, self-reported methods, such as the Test of Adherence to Inhalers (TAI) questionnaire (37) may however provide important qualitative data on the reasons for non-adherence.

Canister weighing can be performed to determine whether patients used their inhaler devices during the treatment period. However, removal of the doses does not prove that the dose has been inhaled by the patient (38).

Another option is measurement of fractional exhaled nitric oxide (FeNO) in patient's breath (39). This is however an indirect measurement that requires frequent measurements, is also impacted by smoking or respiratory tract infections, and is often only available in more specialized hospital settings. A promising future option may be the use of testing in human scalp hair that may provide a measure of long-term drug exposure (40). This method, however, needs more validation.

Generally, the most objective measurer to continuously measure the implementation are EMDs. Some researchers plea they are the "gold standard" to objectively measure adherence in patients with asthma or COPD (8). These devices record each administration, and some can measure the quality of the inhalation technique and give feedback and reminders (8).

Persistence with asthma/COPD therapy is most frequently measured by determining the frequency of pharmacy medication refills. Yet, refill records do not differentiate between the end of a treatment period and the moment of discontinuation. Therefore, this method may overestimate the rates of persistence (8). All in all, most currently used methods have strengths but also several limitations that hamper their value in determining the true rates of adherence.

\section{Factors affecting adberence}

Whether patients are adherent to their (inhaled) medication is determined by multiple demographic, practical and psychological factors (41). For example, adherence to asthma and COPD treatment is influenced by age, costs of the treatment, education, knowledge about the disease and medication, regimen complexity, poor communication with the healthcare professional, adverse effects of the drugs, comorbidities, depression and frailty $(7,8,11)$.

The three phases of adherence are each influenced by specific factors (41). Regarding the initiation phase, one study showed that female patients, younger patients, non-married patients, current smokers and high alcohol users were less likely to start their therapy (42). The implementation of therapy is generally high when (I) patients believe that their asthma is a long-term disease, (II) when patients believe that maintenance treatment is needed to control asthma and (III) when patients are able to manage their inhaler device $(43,44)$. In contrast, implementation is poor in patients who complain about having too much medication, in women and current smokers $(8,31)$. Nonpersistence in COPD is likely to occur in young patients, current smokers, patients with more severe COPD and patients receiving multiple inhalers $(45,46)$. Persistence for patients with asthma is higher when being male, having a prescription for a higher dose therapy, having comorbidities and older age (23).

\section{Clinical and economic consequences of non-adberence in asthma and COPD}

The overall adherence among patients with asthma/ COPD is worse compared to other patients with chronic diseases (47). Variable symptoms, frequent comorbidities and the complex inhaled route of drug administration may be partly responsible (47). The high non-adherence rates 
have several clinical and economic consequences, discussed in further detail below (7).

\section{Clinical consequences of non-adherence in asthma and COPD}

There is a clear negative association between medication non-adherence and poor disease outcomes (7). The main clinical consequence of non-adherence of asthma and COPD treatment is decreased disease control, leading to high exacerbation rates, high symptom rates, increased mortality and disability and reduced quality of life (48). According to the Study of Asthma Phenotypes and Pharmacogenomic Interactions by Race-Ethnicity (SAPPHIRE) trial, 24\% of the asthma exacerbations could be prevented when patients would have been adherent to their inhaled corticosteroids (ICS) (49). Exacerbations are effectively reduced when a patient is adherent for over $75 \%$ of the time $(47,49)$. Partly due to this threshold, most studies define a patient as "good adherent" when they are adherent for over $80 \%$ of the time.

In patients with over $80 \%$ adherence, clinical outcomes improve significantly. Indeed, higher adherence was associated with less hospitalizations, exacerbations and emergency department visits, and with better lung function $(17,50)$. Furthermore, in a post-hoc analysis, good adherence was associated with a lower mortality rate among patients with COPD, although "the healthy adherer effect" (i.e., the phenomenon that good adherence is an indicator for an overall healthier lifestyle) may partly explain this (51). The opposite is true for patients that are poorly adherent: poor adherence is associated with increased healthcare use and mortality (52).

Another consequence of non-adherence for patients with asthma is additional prescription of either potentially harmful or more expensive medication. Patients in the first four steps of GINA use ICS, long-acting $\beta$-agonists (LABA) and/or short-acting $\beta$-agonists (SABA), which are relatively affordable and safe therapies with few side effects. Patients with uncontrolled severe asthma who already receive (or are prescribed) high-dose ICS and LABA could be stepped up to GINA step 5 (53). In this step, patients could receive add-on therapy such as oral corticosteroids (OCS) or monoclonal antibody therapy (e.g., anti-IgE, anti-IL-5). The former cause many side effects which in turn can be expensive (54); the latter are more expensive. However, many patients eligible or using biologics and OCS are nonadherent to their therapy $(14,55)$.

An important factor of non-adherence is a poor inhalation technique: four times as many patients with poor inhalation technique suffer from uncontrolled asthma compared to patients with good inhalation technique. Similarly, exacerbation rates doubled in patients with COPD who made at least one inhalation error (47). On the contrary, clinical outcomes improved over time in patients with asthma/COPD who made less inhalation errors (56). Moreover, good adherence (over $80 \%$ ) is no guarantee for good clinical outcomes, because patients with good adherence, but a poor inhalation technique experienced more exacerbations compared to patients with good inhalation technique (52). In conclusion, nonadherence goes hand in hand with poor clinical outcomes, an adherence rate over $80 \%$ is associated with improved clinical outcomes and inhalation technique should be taken into account when improving adherence.

\section{Economic consequences of non-adherence in asthma and COPD}

The economic consequences are expressed in direct and indirect costs, direct costs are healthcare costs (e.g., hospitalizations, medication) and indirect costs are societal costs (e.g., loss of productivity, missed workdays) (57). Nonadherence in patients with asthma/COPD is associated with high healthcare and societal costs due to exacerbations, hospitalizations, missed school and workdays and loss of productivity $(7,16,17,48)$.

A British study showed that patients experiencing an asthma exacerbation had 3.5 times more healthcare costs compared to those who did not (58). Yet, the economic burden due to asthma is mainly prescribed to the high indirect costs: $62.5 \%$ of the total annual costs per patient were caused by loss of productivity and missed workdays (59). Exacerbations of patients with COPD are suggested to cause $35-45 \%$ of all direct costs associated with COPD (7). A net reduction of healthcare costs of $\$ 300,000$ per thousand patients, annually, was shown when patients with COPD were adherent to their medication compared to when they were non-adherent (60). Therefore, it is plausible that non-adherence is (partly) responsible for high healthcare and societal costs (61).

The economic impact of non-adherence in patients with asthma/COPD is also driven by poor inhalation technique. This has been demonstrated in three countries. In Spain, Sweden and the United Kingdom (UK), the direct annual costs per patient with asthma or COPD were $€ 1421, € 1,183$ and $€ 963$, respectively. A substantial part of these direct costs (i.e., $€ 109$, $€ 55$ and $€ 21$ ) were estimated to be due to 
inhalation errors. When including indirect costs due to inhalation errors, the costs more than doubled (to $€ 271$, $€ 466$ and €506, respectively). Therefore, it seems that poor inhalation technique contributes significantly to the large economic burden of COPD and asthma (3).

The economic case for adherence improvement in COPD mainly lies in the prevention of costly hospitaltreated exacerbations. In asthma, the majority of healthcare costs are spent on medication (62). Further increasing adherence is therefore likely to only increase these healthcare costs, yet many patients with asthma are of working age. As such, if enhanced adherence results in less missed workdays and improved productivity, still a positive return on investment can be expected (62).

\section{Adberence enhancing intervention programs}

Physicians, pharmacists and nurses have a very important role in management of their patients' adherence behavior (63). Many intervention programs aiming at improvement of adherence in patients with asthma/COPD are primary care based. These include the PHARMAceutical Care for COPD (PHARMACOP) trial in Belgium, the Medication Monitoring and Optimization (MeMO) program in the Netherlands and a randomized controlled trial in Spain $(9,19,64)$. These studies show a significantly improved adherence and less hospitalizations in the intervention group, which received information about the disease, the importance of adherence and inhalation technique, compared with the control group receiving usual care $(9,19,64)$.

Another reason for high non-adherence rates is the inability of healthcare professionals to educate their patients about the importance of good adherence and a good inhalation technique (3). It is shown that training healthcare professionals on asthma guidelines, educational skills and communication techniques improved health outcomes of patients with asthma in the US (65).

In line with the fact that many patients have limited knowledge about the disease and its treatment, it is suggested that involving the patient in the decision-making plan of their own treatment may enhance adherence, quality of life and lung function $(41,66,67)$. This finding is described in the shared decision making (SDM) model. SDM describes four key features that are important to involve a patient in their own treatment plan: (I) share relevant information, (II) talk about treatment preferences, (III) discuss the options and (IV) agree on the treatment (66).
Research showed that patients involved in the decisionmaking plan of their own treatment were more adherent and had improved clinical outcomes compared to the patients who were not actively involved in their treatment plan (67).

\section{Smart inhalers: objective, real-time adberence measurement}

An emerging field of inhaler technology makes use of electronic sensors attached to or integrated in the inhaler. These so-called "smart inhalers" can make adherence assessment much more reliable, granular and objective. Smart inhalers come in various forms (see Figure 2), from simple tracking devices only counting the usage of an inhaler, to more sophisticated devices that provide reminders and personalized feedback to patients (106). Smart inhalers can provide objective and real-time data on inhaler use and can as such support adherence management either in combination with a self-management app (standalone option) or to facilitate consultations between patient and healthcare provider. In the latter option, the actual dosing, and sometimes its quality, can be compared with the prescribed dosing and can be used as a starting point for a conversation about non-adherence. In its stand-alone use, smart inhalers can also provide reminders for patients to take their medication and they can give the patient motivation and feedback on daily use and inhaler technique $(63,69)$. Thus, smart inhalers can be used in different aspects of the adherence work-up (see Figure 3). Amongst others, they can be used to (I) detect non-adherence, (II) provide reminders, (III) provide educational and motivation feedback and (IV) to improve inhaler technique. In the following section, we will further illustrate these functionalities.

\section{Using smart inhalers to detect non-adherence}

First, smart inhalers can be used to detect non-adherence. This can be of importance in both daily clinical practice as a starting point for conversation about adherence, or to guide treatment step-up decisions (see Figure 3). Another possible application is in the interpretation of medication effectiveness in the regulatory process during registration trials (107). Currently, in many clinical trials, actual medication use is poorly registered. As such, when the examined medication has no pharmacological effect, it may well be that some participants actually never took the drug without the investigator knowing (108). Of note, 


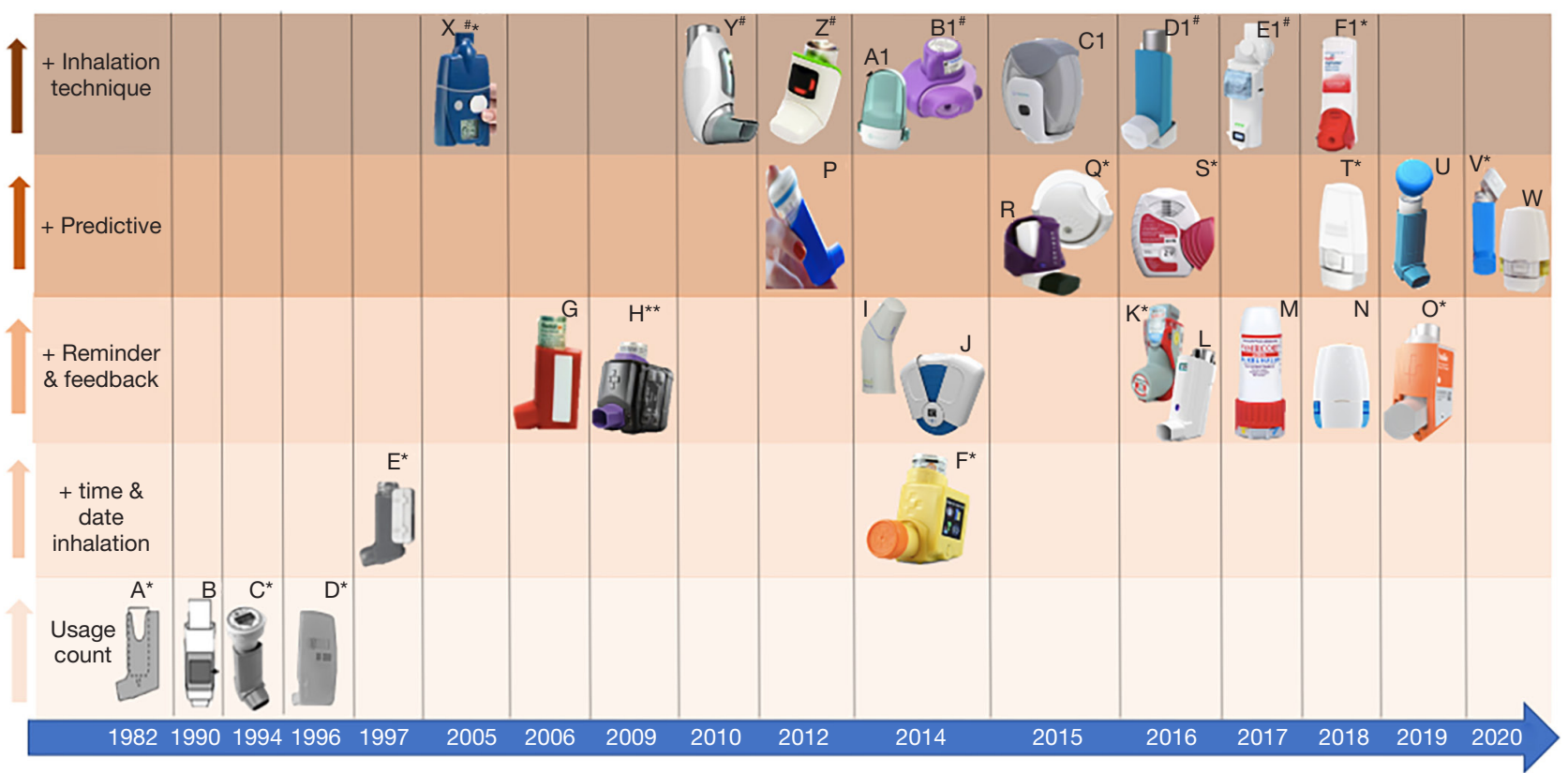

Figure 2 The evolution of smart inhalers over time. (A) Nebulizer Chronolog (68); (B) Aerosol Actuation Counter (MDI) (69); (C) Doser (MDI) (70,71); (D) Smart Mist (MDI) (69,72); (E) MDILog (MDI) (69,73); (F) Smart Touch for Symbicort (MDI) (69,70); (G) SmartInhaler Tracker (pMDI) (69); (H) SmartTrack (MDI) (69,74); (I) Inspiromatic (DPI) (75); (J) Prohaler (DPI) (76); (K) Updated SmartTouch for Symbicort (MDI) (77-79); (L) eMDI (pMDI) (80); (M) Turbu+ (MDI) (81); (N) Electronic Breezhaler (DPI) (82); (O) Hailie for Flovent, available for multiple devices (Ventolin, ProAir, Seretide) (MDI) (83,84); (P) CareTRx (MDI) (69,85); (Q) Propeller sensor Diskus (DPI) (86,87); (R) HeroTracker (DPI \& MDI) (88); (S) GSK Elipta inhaler (propeller sensor) (DPI) (89,90); (T) Propeller sensor for Neohaler (and Breezhaler) (DPI) (91,92); (U) Findair (MDI) (93); (V) Propeller sensor for Symbicort (pMDI) (94); (W) Enerzair Breezhaler (DPI) (95); (X) I-neb (Nebulizer) (96,97); (Y) Verihaler (MDI) (98); (Z) T-haler (MDI) (99); (A1) RSO1 (DPI) (100); (B1) INCA (DPI) (101); (C1) Respiro Sense diskus (DPI), also available for Easyhaler, Zephir, Handihaler and Elipta (102); (D1) Inspair (pMDI) (103); (E1) Pneumahaler (Soft mist inhaler) (104); (F1) Proair Digihaler (mDPI) (105). *, FDA approved smart inhalers; **, Smartdisk (DPI), Smartturbo (DPI), Smartflow (pMDI), Smartmat (SMI) are devices from the same company but not FDA approved. They all have reminder and feedback function and count the number of inhalation and record time and date, but they are suited for different inhaler devices. This company is now Hailie; \#, do predict exacerbations and does not give reminders.

variability in adherence levels of participants can have a significant impact on the required samples size and trial power, and thus costs of the trial (106). Approximately $63 \%$ of the randomized controlled trials examining treatment for patients with severe asthma did not report whether the participants were adherent. Trials examining adherence achieved a significantly higher power (mean power $59 \%$ ) to find expected differences in the forced expiratory volume within one second $\left(\mathrm{FEV}_{1}\right)$ compared with trials that did not examine adherence (mean power $49 \%$ ). Of note, the adherence-examining trials had a lower sample size. It has been suggested that undetected nonadherence is responsible for up to $50 \%$ of the variance in $\mathrm{FEV}_{1}$ results (107).

\section{Using smart inhalers to provide reminders}

Smart inhalers can also serve to remind patients to use their inhaler. It has been shown that patients who received electronic inhaler reminders administered their medication 1.5 times more often compared to patients who did not receive reminders (109).

Table 1 includes an overview of smart inhaler interventions using reminders which have been examined in randomized controlled trials in the past seventeen years. The E-Monitoring of Asthma Therapy to Improve Compliance in children (e-MATIC) trial found that children (aged 4-11 years) receiving short message service (SMS) reminders had a higher adherence rate than the children who did not receive reminders (69.3\% vs. $57.3 \%)$ (113). 


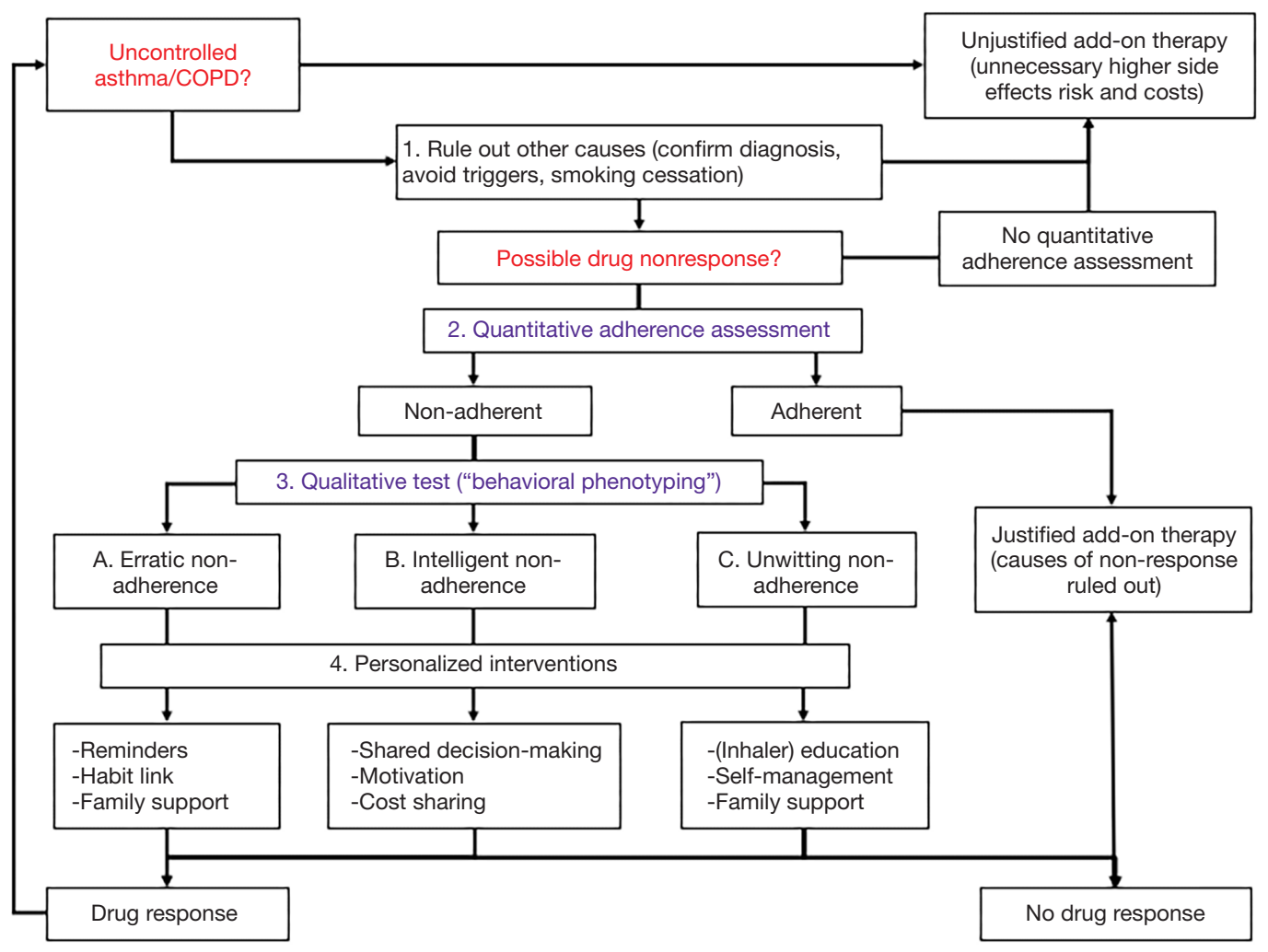

Figure 3 Different types of non-adherence occur among patients with asthma/COPD. The purple boxes represent the steps where smart inhalers could be useful. COPD, chronic obstructive pulmonary disease.

However, there was no reduction in exacerbations, improved quality of life or asthma control in both groups (113). A randomized controlled trial in New Zealand enrolling children with asthma (6-15 years) achieved higher adherence rates in the intervention group (84\% vs. $30 \%$ in the control group) than the Dutch e-MATIC trial while both trials used the same method $(25,113)$. Furthermore, the New Zealand trial found that the children in the intervention group suffered significantly less exacerbations and their lung function improved (25). However, the New Zealand trial recruited children with poor asthma control and low adherence at baseline, while the e-MATIC trial recruited clinically stable patients with asthma $(25,113)$. This divergent inclusion criteria might explain the different results.

EMDs with reminder functions also record time and date of the inhalation maneuvers which explains the adherence behavior of a patient. The STAAR study found that children (6-16 years) receiving reminders and feedback from their clinician about their adherence behavior were significantly more adherent over a period of 12 months than the children whose adherence was monitored but not reviewed and whom did not receive reminders (70\% vs. 49\%) (112). Although the adherence rate did not exceed the $75 \%$ threshold, it did result in a significant decrease in exacerbations and hospitalizations (112).

\section{Using smart inhalers to provide educational and motivational feedback}

Besides reminders, patients can also receive feedback from smart inhalers (Table 1). Biofeedback can be based on time of use, inhaler technique, habit and the relationship between peak flow and adherence (111). Multiple studies show that patients receiving feedback about their inhalation behavior have an increased adherence rate, experience a better quality of life, less symptoms and less seasonal variations $(110,112,114)$. Patients receive a lot more information via these feedback systems compared to usual care. Disadvantages of smart inhalers are that the clinicians and pharmacists have to explain the patient how the 
Table 1 Overview of smart inhaler interventions tested in randomized controlled trials

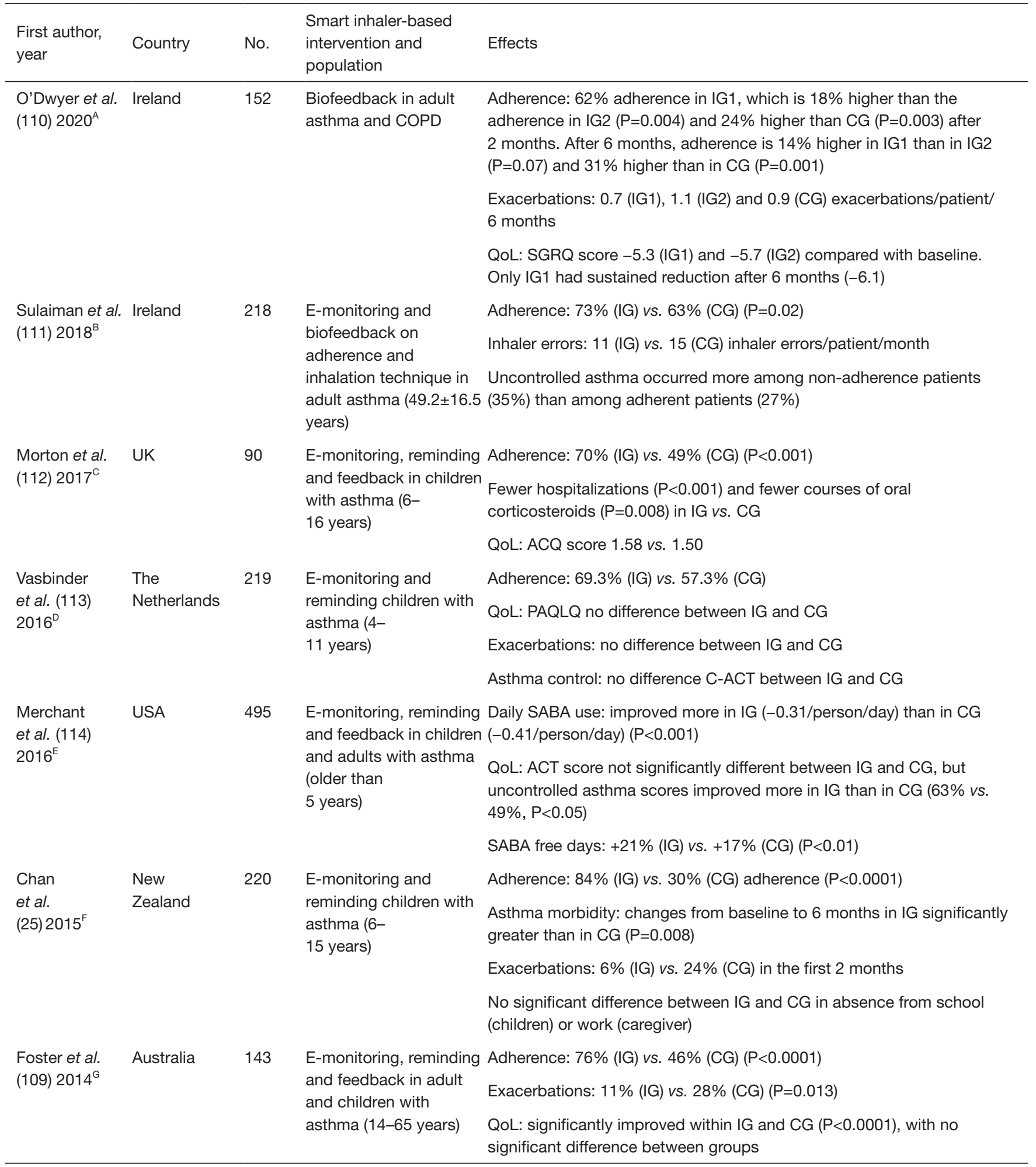

Table 1 (continued) 
Table 1 (continued)

\begin{tabular}{llll}
\hline $\begin{array}{l}\text { First author, } \\
\text { year }\end{array}$ & Country & No. & $\begin{array}{l}\text { Smart inhaler-based } \\
\text { intervention and } \\
\text { population }\end{array}$
\end{tabular}

(A) The St. George Respiratory Questionnaire (SGRQ) scores the QoL between 0 (few limitations) and 100 (many limitations). Reduction of SGRQ score in IG1 and IG2 are significant. Exacerbations: no significant between group differences and no significant within group differences after 2 and 6 months compared with baseline. (B) Difference inhaler errors between IG and CG not significant. (C) Asthma control questionnaire (ACQ) scores the QoL with a score between 0 (totally controlled asthma) and 6 (severely uncontrolled asthma). No significant difference in QoL between IG and CG. (D) Pediatric asthma quality of life questionnaire (PAQLQ) scores the QoL of children with a score between 0 (uncontrolled asthma) and 27 (controlled asthma). C-ACT is the childhood asthma control test which scores asthma control between 0 (uncontrolled asthma) and 25 (controlled asthma). (E) The asthma control test (ACT) scores the asthma control between 0 (uncontrolled asthma) and 25 (controlled asthma). Adherence was not measured. Short-acting $\beta$-agonists (SABA) free days increased significantly in IG vs. CG. (F) Proportion of patients experiencing more than 1 exacerbation in the first 2 months. No difference in exacerbations between IG and CG after 6 months. Asthma morbidity measured with C-ACT. (G) No significant difference in proportion of patients experiencing more than one exacerbation in 6 months in IG group vs. CG group. QoL measured with ACT. (H) QoL between IG and CG not significant. QoL was measured using the ACQ. (I) No significant differences AQLQ score between IG and CG. Asthma quality of life question (AQLQ) scores the QoL of adult patients with asthma between 0 (not impaired) and 7 (severely impaired). IG1 = intervention group 1, IG2 = intervention group 2. IG, intervention group; CG, control group; QoL, quality of life.

smart inhaler needs to be handled, which takes time and causes a higher workload for healthcare professionals (70). On the other hand, healthcare professionals do not need to monitor the adherence of patients themselves and patients have better clinical outcomes, which will cause less general practitioner visits and healthcare costs. Furthermore, there is technology emerging that combines environmental triggers (e.g., allergens and pollution) causing asthma attacks with the location of the patient. When the patient is exposed to the same set of triggers in the future, the smart inhaler could warn the patient for a possible exacerbation (106).

\section{Using smart inhalers to improve inhalation technique}

As many patients with asthma/COPD have a poor inhalation technique, the latter is an important factor of non-adherence. Smart inhalers could be useful in monitoring inhalation technique (Table 1) (70). Both the inhalation technique of DPI and pMDI users can be monitored. An example is the inhaler compliance assessment device (INCA), which can detect inhaler errors by audio recording (11). Patients receiving intensive education about the importance of adherence and inhalation technique and who received biofeedback from the INCA had an increased adherence rate and an improved inhalation technique compared to patients who only received intensive education (111). A limitation of this smart inhaler was that numerous inhalation recordings are needed to estimate the peak inspiratory flow rate and the inspiratory capacity (111). Therefore, researchers examined a more efficient and faster method to calibrate flow-sound models to estimate the entire flow profile of 
inhalation. This method uses the logarithmic relationship between the flow signal and the acoustic envelope of the sound of inhalation (12).

\section{Patient experiences with smart inhalers}

Patients with asthma, adults as well as children, are generally positive about the use of smart inhalers $(118,119)$. Patients with moderate to severe asthma were positive about the reminder function and the adherence feedback of the SmartTrack device (Adherium, Auckland, New Zealand) $(118,120)$. The reminder function "trained" these patients to be adherent and encouraged them to make inhaler use a daily habit (118). Furthermore, the reminder function made children feel more in control over their asthma compared to children who did not have access to the reminder function (120). Patients with asthma who only used their inhaler symptomatically were less positive about the reminder function (118). A positive aspect of the use of smart inhalers is that patients with asthma feel responsible for their therapy (119). The feedback function of smart inhalers was generally considered as positive, but patients prefer certain methods over others (e.g., email, smartphone app) (119). The device ergonomics are important to consider when developing a smart inhaler (120). Adults found the SmartTrack easy to use, but up to $16 \%$ of the children using the SmartTrack device reported it as "too big" (118-121). Another issue that may be relevant is whether patients want to share their adherence data recorded by the smart inhaler with health care professionals. Patients do see the benefits of sharing adherence information, but they also consider the negative implications of sharing adherence data (119).

\section{Cost-effectiveness of improved adberence}

Programs that increase adherence and quality of life may improve clinical outcomes. Yet, interventions also come at a price and therefore, to assess whether they do provide value for money, their cost-effectiveness is important. The effects of a cost-effectiveness analysis are expressed in qualityadjusted life years (QALY), which is a measure for the quantity and quality of the life lived - one QALY represents 1 year in perfect health (57). As has been highlighted before, increased adherence could reduce costs, due to amongst others, less hospitalizations, more productive workdays, and an increased quality of life $(7,60,122,123)$. Whether these can counterbalance the additional costs of the intervention is an issue of debate.
The PHARMACOP-intervention program in Belgium was able to improve adherence and inhalation technique in patients with COPD and decrease hospitalizations (9). The accompanying cost-effectiveness study showed that this would lead to total cost savings of $€ 227$ per patient, compared to usual care (122). The initial costs for the PHARMACOP-intervention were $€ 161$ per patient higher compared to usual care, but they were offset by $€ 388$ per patient savings due to the fact less exacerbations had to be treated (122).

Not many studies examined the cost-effectiveness of improving adherence to asthma therapy, except for the hypothetical USA model study of Zafari et al. (124). This study found that over a 10-year time period, full-adherence to therapy cost $\$ 3,187$ per patients more, prevented 2.26 exacerbations per patient and caused 0.13 QALY gain per patient compared with usual care. Therefore, the incremental cost effectiveness ratio (ICER) was estimated at \$24,515/QALY (57). The ICER decreased drastically when the prevention of indirect costs (i.e., work productivity) due to full adherence were included (124). In conclusion, both in asthma and COPD, limited evidence indicates that intervention programs to improve adherence are costeffective.

\section{Cost-effectiveness of smart inhalers}

Most smart inhalers are available for prices that range between $\$ 100$ and $\$ 500$ per device (10). Additional differences occur in the battery life of the devices. The SmartTrack for example, has a battery life of approximately 58 days (121) while some Hailie devices have rechargeable batteries (83). Therefore, it is yet unknown whether smart inhalers provide a favorable return on investment. To our knowledge, only an exploratory cost-effectiveness analysis examining the costs and benefits of the use of smart inhaler intervention therapy in patients with COPD has yet been performed (125). It showed that the use of the INCA smart inhaler for patients with poor adherence and a good inhaler technique caused an annual cost saving of $€ 845$ per patient. The use of INCA in patients with good adherence and poor technique and in patients with poor adherence and poor technique was also cost-effective, but not cost-saving (125). This suggests that smart inhalers targeting patient-specific inhaler technique and adherence profiles could potentially improve clinical and economic outcomes of patients with COPD (106).

Yet, given the scarcity of evidence, future clinical trials 
are needed that include robust economic outcomes and cost-effectiveness analyses. Clinical outcomes should furthermore include exacerbation rate, the clinical stability of patients, whether inflammatory biomarkers change when adherence rates change, and whether loss of lung function can be prevented (126). The latter is very interesting due to the fact that up to $50 \%$ of the patients with symptomatic asthma do not have T2 cytokine driven eosinophilic airway inflammation which makes them less sensitive for steroid therapy $(127,128)$. Therefore, to be able to interpret changes in lung function and symptoms when adherence is improved due to smart inhalers, the inflammatory biology of patients should also be examined (126).

\section{Future perspective}

\section{Challenges to overcome}

To fully integrate smart inhalers in daily clinical care, several challenges must be overcome. For example, apps and software are now developed for each device separately (Figure 2) (10,69), and they all need to be integrated in medical patient management systems. This is hard to organize, and it may confuse patients and increase the workload for healthcare professionals. Ideally, the data derived from the smart inhaler should be easy to interpret, compatible between smart inhalers from different manufacturers, and the data uploads should be seamlessly integrated into one single patient management platform $(63,70)$.

Furthermore, technical aspects of smart inhalers should be as easy as possible to prevent time consuming training for healthcare professionals and patients and technical issues should be resolved before a smart inhaler is used in usual care. In an earlier study, several technical issues of smart inhalers were reported, e.g., not recording doses (broken switch or mechanical damage), nozzle blockade and low battery. By identifying technical malfunctions during pre-use studies and within-studies, technical issues can be resolved which makes them more feasible for integration in real-world usual care (129). The material used to construct the smart inhalers should also be considered in detail. It should be robust to prevent breakage and it should preferably be biological degradable or recyclable to minimize environmental impact $(63,70)$.

Smart inhalers should meet the regulatory requirements of the Food and Drug Administration (FDA) and other regulatory bodies such as the European Medicines Agency
(EMA). The FDA and EMA may still challenge the evidence that smart inhalers improve clinical outcomes and quality of life (130). The studies conducted so far showed a significantly improved adherence in both children and adults when using smart inhalers (Table 1) (25,109-117). However, not all trials show a decrease in exacerbations and hospitalizations and an improved quality of life and lung function $(109,112,113)$.

The costs of smart inhalers are another challenge to overcome. The costs should be acceptable to payers (e.g., patients, health insurances etc.) and manufactures (10). Until now, only one exploratory modeling study indicated that smart inhalers could be cost-saving in patients with COPD (125). Another challenge is related to the payer. For example, are smart inhalers going to be available over-the-counter or compensated by the insurer? To solve this problem, manufacturers can integrate the smart inhaler into the inhalation device to make the smart inhaler part of asthma/ COPD medication, which are commonly reimbursed (131). Another issue: can insurers see the adherence data of the assurer? The latter is mainly important when employers provide the insurance. Employers should not be able to see the adherence data of their employee and penalize them for it (63).

This brings us to another important issue of smart inhalers: can smart inhalers guarantee the privacy of users? (130) A total of $59 \%$ of the questioned patients with asthma/COPD in the UK and US do not want to use an app connected to the smart inhaler which gives reminders and feedback about the adherence and inhalation technique, because the app gives them the "big brother is watching you" feeling (70). Thus, still some challenges need to be overcome before smart inhalers are fully ready for realworld patient care.

\section{Smart inbalers for specific patient groups}

While the exact cost-effectiveness in the overall group of patients with asthma or COPD is not determined yet, smart inhalers are likely to be cost-effective in specific subgroups of patients with asthma/COPD. For example, one subgroup consists of patients with uncontrolled asthma who are nonadherent in GINA-4. By improving the adherence rate in these patients, their asthma could be controlled, preventing those patients from going to more expensive or harmful medication (55). For example, GINA-5 includes treatment with OCS, which causes many side effects, and biologics, which are very expensive. It is shown that patients who 
already receive OCS or biologics are also poorly adherent to ICS (132). Maintenance treatment to ICS is still needed in GINA-5 to control asthma (132). By improving adherence in these patients, therapy can be optimized, improving clinical outcomes.

Another subgroup in which smart inhalers are likely to be cost-effective are patients with severe COPD who often experience exacerbations and hospitalizations. These patients cause high healthcare costs while the adherence rate is only $40 \%$ (42). Improved adherence improves clinical outcomes in patients with COPD which results in lower healthcare costs. When COPD cannot be controlled with the usual LABA/long-acting muscarinic-antagonists (LAMA) therapy, triple therapy can be assessed. This therapy consists of ICS/LABA/LAMA and is usually more expensive than dual therapy (133). By improving adherence in uncontrolled patients with COPD, exacerbations and hospitalizations could be reduced and triple therapy may be prevented or delayed.

A fourth potentially cost-effective subgroup are patients with asthma with SABA overuse which indicates uncontrolled asthma. However, $6.6 \%$ to $16 \%$ of patients overusing SABA are not using ICS at all and $57 \%$ are non-adherent to ICS half of the time $(114,134)$. Another subgroup are patients with asthma/COPD of working age. Patients with asthma/COPD are not able to work during exacerbations, severe symptomatic periods and hospitalizations which results in high indirect costs $(3,4,59)$. Approximately $25 \%$ of the working-age patients with COPD quit work due to COPD (135) and up to $47 \%$ of the patients in low-income countries lost their job due to asthma (136). By increasing adherence, asthma and COPD can be controlled in many patients, which results in less healthcare costs and less missed working days.

A subgroup different from the "high-risk-highgain" subgroups mentioned above, are the patients with asthma/COPD who start taking their medication for the first time. When these patients receive short-term, but properly intense smart inhaler-informed education and habit formation, right from the moment they start their treatment, their adherence behavior may become an integrated part of their life, preventing possible bad adherence behavior in the future (131).

\section{Conclusions}

In conclusion, medication non-adherence is prevalent in patients with asthma and COPD and places a high burden on patients and societies around the world. Smart inhalers seem very promising to monitor and manage medication adherence in these patients, ultimately improving clinical outcomes and quality of life and reducing the high economic burden. It is likely that smart inhalers are costeffective, especially when used in high-risk subgroups of patients, however more research is needed to confirm this. Before implementing smart inhalers in usual care, some aspects should be considered and optimized. Especially, the privacy of patients has to be secured, the data should be easy to interpret, uniform between different smart inhalers, and the benefits of the smart inhalers should outweigh the costs.

\section{Acknowledgments}

Funding: None.

\section{Footnote}

Reporting Checklist: The authors have completed the Narrative Review reporting checklist. Available at http:// dx.doi.org/10.21037/jtd-20-2360

Conflicts of Interest: All authors have completed the ICMJE uniform disclosure form (available at http://dx.doi. org/10.21037/jtd-20-2360). Dr. HAMK reports research grants from GSK, Novartis, and Boehringer, and fees for consultancies in advisory boards from Chiesi, GSK, Novartis, and Boehringer, all paid to his institution. Dr. JWHK reports grants and non-financial support from AstraZeneca, grants and non-financial support from Boehringer Ingelheim, grants from Chiesi Pharmaceuticals, grants and non-financial support from GSK, grants from Novartis, grants from MundiPharma, grants from TEVA, from null, outside the submitted work; and Dr. JWHK holds $72.5 \%$ of shares in the General Practitioners Research Institute. Dr. JFMvB reports grants from AstraZeneca, grants and personal fees from Chiesi, personal fees from Teva, grants and personal fees from Trudell medical, personal fees from Novartis, personal fees from Boehringer Ingelheim, outside the submitted work and all paid to his institution. Dr. JFMvB receives funding from European Commission COST Action 19132 (European Network to Advance Best practices \& technoLogy on medication adherence). The authors have no other conflicts of interest to declare.

Ethical Statement: The authors are accountable for all 
aspects of the work in ensuring that questions related to the accuracy or integrity of any part of the work are appropriately investigated and resolved.

Open Access Statement: This is an Open Access article distributed in accordance with the Creative Commons Attribution-NonCommercial-NoDerivs 4.0 International License (CC BY-NC-ND 4.0), which permits the noncommercial replication and distribution of the article with the strict proviso that no changes or edits are made and the original work is properly cited (including links to both the formal publication through the relevant DOI and the license). See: https://creativecommons.org/licenses/by-nc-nd/4.0/.

\section{References}

1. GBD 2015 Chronic Respiratory Disease Collaborators. Global, regional, and national deaths, prevalence, disability-adjusted life years, and years lived with disability for chronic obstructive pulmonary disease and asthma, 1990-2015: a systematic analysis for the Global Burden of Disease Study 2015. Lancet Respir Med 2017;5:691-706. Erratum in: Lancet Respir Med. 2017 Oct;5(10):e30. doi: 10.1016/S2213-2600(17)30336-3. Epub 2017 Sep 14.

2. European Resiratory Society. European lung white book. 2013. Available online: http://www.erswhitebook.org/ chapters/. Accessed at May 6, 2020.

3. Lewis A, Torvinen S, Dekhuijzen PN, et al. The economic burden of asthma and chronic obstructive pulmonary disease and the impact of poor inhalation technique with commonly prescribed dry powder inhalers in three European countries. BMC Health Serv Res 2016;16:251.

4. Jansson SA, Backman H, Andersson M, et al. Severe asthma is related to high societal costs and decreased health related quality of life. Respir Med 2020;162:105860.

5. Vestbo J, Calverley P, Celli B, et al. The TORCH (TOwards a Revolution in COPD Health) survival study protocol. Eur Respir J 2004;24:206-10.

6. Virchow JC, Kuna P, Paggiaro P, et al. Single inhaler extrafine triple therapy in uncontrolled asthma (TRIMARAN and TRIGGER): two double-blind, parallel-group, randomised, controlled phase 3 trials. Lancet 2019;394:1737-49.

7. Mäkelä MJ, Backer V, Hedegaard M, et al. Adherence to inhaled therapies, health outcomes and costs in patients with asthma and COPD. Respir Med 2013;107:1481-90.

8. Vrijens B, Dima AL, Van Ganse E, et al. What we mean when we talk about adherence in respiratory medicine. J
Allergy Clin Immunol Pract 2016;4:802-12.

9. Tommelein E, Mehuys E, Van Hees T, et al. Effectiveness of pharmaceutical care for patients with chronic obstructive pulmonary disease (PHARMACOP): A randomized controlled trial. Br J Clin Pharmacol 2014;77:756-66.

10. Chan AHY, Harrison J, Black PN, et al. Using electronic monitoring devices to measure inhaler adherence: a practical guide for clinicians. J Allergy Clin Immunol Pract 2015;3:335-49.e1-5.

11. Sulaiman I, Cushen B, Greene G, et al. Objective assessment of adherence to inhalers by patients with chronic obstructive pulmonary disease. Am J Respir Crit Care Med 2017;195:1333-43.

12. Taylor TE, Lacalle Muls H, Costello RW, et al. Estimation of inhalation flow profile using audio-based methods to assess inhaler medication adherence. PLoS One 2018; 13:e0191330.

13. World Health Organization. Adherence to long-term therapies: evdence for action. Last update 2003. Available online: http://www.who.int/chronic-conditions/en/ adherence-report. Accessed May 6, 2020.

14. van Boven JFM, Koponen M, Lalic S, et al. Trajectory analyses of adherence patterns in a real-Life moderate to severe asthma population. J Allergy Clin Immunol Pract 2020;8:1961-1969.e6.

15. Belleudi V, Di Martino M, Cascini S, et al. The impact of adherence to inhaled drugs on 5 -year survival in COPD patients: a time dependent approach. Pharmacoepidemiol Drug Saf 2016;25:1295-304.

16. Kim JA, Lim MK, Kim K, et al. Adherence to inhaled medications and its effect on healthcare utilization and costs among high-grade chronic obstructive pulmonary disease patients. Clin Drug Investig 2018;38:333-40.

17. Chen R, Gao Y, Wang H, et al. Association Between Adherence to Maintenance Medication in Patients with COPD and Acute Exacerbation Occurrence and Cost in China: A Retrospective Cohort Database Study. Int J Chron Obstruct Pulmon Dis 2020;15:963-71.

18. Cramer JA, Bradley-Kennedy C, Scalera A. Treatment persistence and compliance with medications for chronic obstructive pulmonary disease. Can Respir J 2007;14:25-9.

19. Leiva-Fernández J, Leiva-Fernández F, García-Ruiz A, et al. Efficacy of a multifactorial intervention on therapeutic adherence in patients with chronic obstructive pulmonary disease (COPD): a randomized controlled trial. BMC Pulm Med 2014;14:70.

20. Desalu OO, Onyedum CC, Adeoti AO, et al. Guidelinebased COPD management in a resource-limited setting 
- physicians' understanding, adherence and barriers: A cross-sectional survey of internal and family medicine hospital-based physicians in Nigeria. Prim Care Respir J 2013;22:79-85.

21. Salinas GD, Williamson JC, Kalhan R, et al. Barriers to adherence to chronic obstructive pulmonary disease guidelines by primary care physicians. Int J Chron Obstruct Pulmon Dis 2011;6:171-9.

22. Chatkin JM, Blanco DC, Scaglia N, et al. Impact of a low-cost and simple intervention in enhancing treatment adherence in a Brazilian asthma sample. J Asthma 2006;43:263-6.

23. Bender BG, Pedan A, Varasteh LT. Adherence and persistence with fluticasone propionate/salmeterol combination therapy. J Allergy Clin Immunol 2006;118:899-904.

24. Abegaz TM, Shegena EA, Gessie NF, et al. Barriers to and competency with the use of metered dose inhaler and its impact on disease control among adult asthmatic patients in Ethiopia. BMC Pulm Med 2020;20:48. Erratum in: BMC Pulm Med. 2020 Apr 20;20(1):95. doi: 10.1186/ s12890-020-1122-1.

25. Chan AH, Stewart AW, Harrison J, et al. The effect of an electronic monitoring device with audiovisual reminder function on adherence to inhaled corticosteroids and school attendance in children with asthma: a randomised controlled trial. Lancet Respir Med 2015;3:210-9.

26. Ding B, Small M. Disease burden of mild asthma in China. Respirology 2018;23:369-77.

27. Bereznicki BJ, Chapman MP, Bereznicki LRE. Factors associated with overestimation of asthma control: A crosssectional study in Australia. J Asthma 2017;54:439-46.

28. Al-Jahdali H, Wali S, Salem G, et al. Asthma control and predictive factors among adults in Saudi Arabia: Results from the Epidemiological Study on the Management of Asthma in Asthmatic Middle East Adult Population study. Ann Thorac Med 2019;14:148-54.

29. Latry P, Pinet M, Labat A. et al. Adherence to antiinflammatory treatment for asthma in clinical practice in France. Clin Ther 2008;30:1058-68.

30. Manfrin A, Tinelli M, Thomas T, et al. A cluster randomised control trial to evaluate the effectiveness and cost-effectiveness of the Italian medicines use review (I-MUR) for asthma patients. BMC Health Serv Res 2017;17:300.

31. Westerik JAM, Carter V, Chrystyn H, et al. Characteristics of patients making serious inhaler errors with a dry powder inhaler and association with asthma-related events in a primary care setting. J Asthma 2016;53:321-9.

32. Lavorini F, Magnan A, Christophe Dubus J, et al. Effect of incorrect use of dry powder inhalers on management of patients with asthma and COPD. Respir Med 2008;102:593-604.

33. Price DB, Román-Rodríguez M, McQueen RB, et al. Inhaler errors in the CRITIKAL study: type, frequency, and association with asthma outcomes. J Allergy Clin Immunol Pract 2017;5:1071-1081.e9.

34. Roggeri A, Micheletto C, Roggeri DP. Inhalation errors due to device switch in patients with chronic obstructive pulmonary disease and asthma: critical health and economic issues. Int J Chron Obstruct Pulmon Dis 2016;11:597-602.

35. Chrystyn H, Price DB, Molimard M, et al. Comparison of serious inhaler technique errors made by device-naïve patients using three different dry powder inhalers: a randomised, crossover, open-label study. BMC Pulm Med 2016;16:12.

36. Tommelein E, Mehuys E, Van Tongelen I, et al. Accuracy of the medication adherence report scale (MARS-5) as a quantitative measure of adherence to inhalation medication in patients with COPD. Ann Pharmacother 2014;48:589-95.

37. Plaza V, Fernández-Rodríguez C, Melero C, et al. Validation of the "Test of the Adherence to Inhalers" (TAI) for asthma and COPD Patients. J Aerosol Med Pulm Drug Deliv 2016;29:142-52.

38. Rand CS, Nides M, Cowles MK, et al. Long-term metered-dose inhaler adherence in a clinical trial. The Lung Health Study Research Group. Am J Respir Crit Care Med 1995;152:580-8.

39. Heaney LG, Busby J, Bradding P, et al. Remotely monitored therapy and nitric oxide suppression identifies nonadherence in severe asthma. Am J Respir Crit Care Med 2019;199:454-64.

40. Hassall D, Brealey N, Wright W, et al. Hair analysis to monitor adherence to prescribed chronic inhaler drug therapy in patients with asthma or COPD. Pulm Pharmacol Ther 2018;51:59-64.

41. Bourbeau J, Bartlett SJ. Patient adherence in COPD. Thorax 2008;63:831-8.

42. Restrepo RD, Alvarez MT, Wittnebel LD, et al. Medication adherence issues in patients treated for COPD. Int J Chron Obstruct Pulmon Dis 2008;3:371-84.

43. Foster JM, Smith L, Bosnic-Anticevich SZ, et al. Identifying patient-specific beliefs and behaviours for conversations about adherence in asthma. Intern Med J 2012;42:e136-44. 
44. Souza-Machado A, Santos PM, Cruz ÁA. Adherence to treatment in severe asthma predicting factors in a program for asthma control in Brazil. World Allergy Organ J 2010;3:48-52.

45. Tanaka K, Kamiishi N, Miyata J, et al. Determinants of Long-Term Persistence with Tiotropium Bromide for Chronic Obstructive Pulmonary Disease. COPD 2015;12:233-9.

46. Yu AP, Guérin A, Ponce De Leon D, et al. Therapy persistence and adherence in patients with chronic obstructive pulmonary disease: multiple versus single longacting maintenance inhalers. J Med Econ 2011;14:486-96.

47. Dekhuijzen R, Lavorini F, Usmani OS, et al. Addressing the impact and unmet needs of nonadherence in asthma and chronic obstructive pulmonary disease: where do we go from here? J Allergy Clin Immunol Pract 2018;6:785-93.

48. Kaplan A, Price D. Treatment adherence in adolescents with asthma. J Asthma Allergy 2020;13:39-49.

49. Williams LK, Peterson EL, Wells K, et al. Quantifying the proportion of severe asthma exacerbations attributable to inhaled corticosteroid nonadherence. J Allergy Clin Immunol 2011;128:1185-1191.e2.

50. van Boven JF, Chavannes NH, van der Molen T, et al. Clinical and economic impact of non-adherence in COPD: a systematic review. Respir Med 2014;108:103-13.

51. Vestbo J, Anderson JA, Calverley PMA, et al. Adherence to inhaled therapy, mortality and hospital admission in COPD. Thorax 2009;64:939-43.

52. Cushen B, Sulaiman I, Greene G, et al. The clinical impact of different adherence behaviors in patients with severe chronic obstructive pulmonary disease. Am J Respir Crit Care Med 2018;197:1630-3.

53. Muneswarao J, Hassali MA, Ibrahim B, et al. It is time to change the way we manage mild asthma: an update in GINA 2019. Respir Res 2019;20:183.

54. Price DB, Trudo F, Voorham J, et al. Adverse outcomes from initiation of systemic corticosteroids for asthma: Long-term observational study. J Asthma Allergy 2018;11:193-204.

55. Lee J, Tay TR, Radhakrishna N, et al. Nonadherence in the era of severe asthma biologics and thermoplasty. Eur Respir J 2018;51:1701836.

56. Kocks JWH, Chrystyn H, van der Palen J, et al. Systematic review of association between critical errors in inhalation and health outcomes in asthma and COPD. NPJ Prim Care Respir Med 2018;28:43.

57. van Boven JFM, van de Hei SJ, Sadatsafavi M. Making sense of cost-effectiveness analyses in respiratory medicine: a practical guide for non-health economists. Eur Respir J 2019;53:1801816.

58. Hoskins G, McCowan C, Neville RG, et al. Risk factors and costs associated with an asthma attack. Thorax 2000;55:19-24.

59. Accordini S, Corsico AG, Braggion M, et al. The Cost of Persistent Asthma in Europe: An International PopulationBased Study in Adults. Int Arch Allergy Immunol 2013;160:93-101.

60. Toy EL, Beaulieu NU, McHale JM, et al. Treatment of COPD: relationships between daily dosing frequency, adherence, resource use, and costs. Respir Med 2011;105:435-41.

61. Simoni-Wastila L, Wei YJ, Qian J, et al. Association of chronic obstructive pulmonary disease maintenance medication adherence with all-cause hospitalization and spending in a medicare population. Am J Geriatr Pharmacother 2012;10:201-10.

62. van Boven JF, Ryan D, Eakin MN, et al. Enhancing Respiratory Medication Adherence: The Role of Health Care Professionals and Cost-Effectiveness Considerations. J Allergy Clin Immunol Pract 2016;4:835-46.

63. Hew M, Reddel HK. Integrated adherence monitoring for inhaler medications. JAMA 2019;321:1045-6.

64. van Boven JFM, Stuurman-Bieze AGG, Hiddink EG, et al. Medication monitoring and optimization: a targeted pharmacist program for effective and cost-effective improvement of chronic therapy adherence. J Manag Care Spec Pharm 2014;20:786-92.

65. Cabana MD, Slish KK, Evans D, et al. Impact of physician asthma care education on patient outcomes*. Health Educ Behav 2014;41:509-17.

66. Charles C, Gafni A, Whelan T. Shared decision-making in the medical encounter: What does it mean? (Or it takes at least two to tango). Soc Sci Med 1997;44:681-92.

67. Wilson SR, Strub P, Buist AS, et al. Shared treatment decision making improves adherence and outcomes in poorly controlled asthma. Am J Respir Crit Care Med 2010;181:566-77.

68. Food and Drug Administration: Nebulizer Chronolog. 510(K) Number: 823423. Available online: https://www. accessdata.fda.gov/scripts/cdrh/cfdocs/cfPMN/pmn. cfm?ID=K823423. Accessed May 1, 2020.

69. Kikidis D, Konstantinos V, Tzovaras D, et al. The digital asthma patient: the history and future of inhaler based health monitoring devices. J Aerosol Med Pulm Drug Deliv 2016;29:219-32.

70. Chrystyn H, Audibert R, Keller M, et al. Real-life inhaler 
adherence and technique: Time to get smarter! Respir Med 2019;158:24-32.

71. Food and Drug Administration: Doser. 510(K) Number: 935955. Available online: https://www.accessdata.fda. gov/scripts/cdrh/cfdocs/cfpmn/pmn.cfm?ID=K935955. Accessed May 1, 2020.

72. Food and Drug Admistration: Smart Mist. 510(K) Number: 960593. Available online: https://www. accessdata.fda.gov/scripts/cdrh/cfdocs/cfPMN/pmn. cfm?ID=K960593. Accessed May 1, 2020.

73. Food and Drug Administration: MDILog. 510(K) Number: 970344. Available online: https://www. accessdata.fda.gov/scripts/cdrh/cfdocs/cfpmn/pmn. cfm?ID=K970344. Accessed May 1, 2020.

74. Food and Drug Administration: Smart Track. 510(K) Number: K091803. Available online: https://www. accessdata.fda.gov/scripts/cdrh/cfdocs/cfPMN/pmn. cfm?ID=K091803. Accessed May 1, 2020.

75. Inspiromatic. Available online: https://www.trendlines. com/company/inspiro-medical/. Accessed May 6, 2020.

76. Prohaler. Available online: https://pharma.aptar.com/en-us/ dispensing-solutions/prohalerr.html. Accessed May 6, 2020.

77. Food and Drug Administration: SmartTouch. 510(K) Number: K133951 (2014) and K173310 (2016). Available online: https:/www.accessdata.fda.gov/scripts/cdrh/ cfdocs/cfPMN/pmn.cfm?ID=K133951 and https://www. accessdata.fda.gov/scripts/cdrh/cfdocs/cfpmn/pmn. cfm?ID=K173310. Accessed May 6, 2020.

78. SmartTouch. Available online: http://www.adherium.com. Accessed May 6, 2020.

79. Food and Drug Administration: Propeller Symbicort. 510(K) Number: K192724. Available online: https:// www.accessdata.fda.gov/scripts/cdrh/cfdocs/cfpmn/pmn. cfm?ID=K192724. Accessed May 5, 2020.

80. eMDI. Available online: https://www.presspart.com/ products/emdi/. Accessed May 6, 2020.

81. SmartTurbo (Turbo+) for Symbicort. Available online: http://www.adherium.com. Accessed June 16, 2020.

82. Electronic Breezhaler. Available online: https://www. cambridgeconsultants.com/insights/peer-reviewedresearch/adding-electronics-breezhalerr-satisfying-needspatients-and. Accessed May 5, 2020.

83. Food and Drug Administration: Hailie, Flovent HVA. 510(K) Number: K182573. Available online: https:// www.accessdata.fda.gov/scripts/cdrh/cfdocs/cfpmn/pmn. cfm?ID=K182573. Accessed May 1, 2020.

84. Hailie, Flovent HVA. Available online: https://www.hailie. com. Accessed May 6, 2020.
85. CareTRx. Available online: https://healthtechinsider. com/2015/10/28/sensors-inhaler-better-asthmamanagement-not-directly-wearable-still-can/. Accessed May 6, 2020.

86. Food and Drug Administration: Propeller Sensor Diskus. 510(K) Number: K152882 and K143671. Available online: https://www.accessdata.fda.gov/scripts/cdrh/cfdocs/cfpmn/ pmn.cfm?ID=K152882 and https://www.accessdata.fda. gov/scripts/cdrh/cfdocs/cfpmn/pmn.cfm?ID=K143671. Accessed May 1, 2020.

87. Propeller Sensor Diskus. Available online: https://www. propellerhealth.com. Accessed May 6, 2020.

88. HeroTracker. Available online: https://coherohealth.com/ products/. Accessed May 6, 2020.

89. Food and Drug Administration: GSK Ellipta Inhaler. 510(K) Number: K161454. Available online: https:// www.accessdata.fda.gov/scripts/cdrh/cfdocs/cfpmn/pmn. cfm?ID=K161454. Accessed May 1, 2020.

90. GSK Ellipta Inhaler. Available online: https://www. propellerhealth.com/press/press-release/propeller-healthreceives-fda-clearance-for-the-propeller-platform-inassociation-with-gsks-ellipta-inhaler/. Accessed May 1, 2020.

91. Food and Drug Administration: Propeller Sensor Breezhaler and Neohaler. 510(K) Number: K180770. Available online: Https:/www.accessdata.fda.gov/scripts/cdrh/cfdocs/cfpmn/ pmn.cfm?ID=K180770. Accessed May 5, 2020.

92. Propeller Sensor Breezhaler and Neohaler. Available online: https://www.propellerhealth.com. Accessed May 6, 2020.

93. Findair. Available online: https://findair.eu. Accessed May 5, 2020.

94. Propeller Symbicort. Available online: https://www. propellerhealth.com. Accessed May 5, 2020.

95. Enerzair Breezhaler. Available online: https://www.ema. europa.eu/en/medicines/human/summaries-opinion/ enerzair-breezhaler. Accessed May 5, 2020.

96. Food and Drug Administration: I-Neb. 510(K) Number: 052941. Available online: https://www.accessdata.fda. gov/scripts/cdrh/cfdocs/cfpmn/pmn.cfm?ID=K052941. Accessed May 5, 2020.

97. Neb. Available online: https://www.philips.co.uk/ healthcare/product/HC85167/i-neb-battery-powereddrug-delivery-system. Accessed May 6, 2020.

98. Verihaler. Available online: https://www.sagentia.com/ case-study/verihaler/. Accessed May 6, 2020.

99. T-Haler. Inhaler Training Device. Available online: https://www.theverge.com/2012/3/13/2866135/t-halerdigital-inhaler-battling-asthma-interactive-game. Accessed 
May 6, 2020.

100. RSO1. Available online: https://rs01x.com. Accessed May 6, 2020.

101.INCA. Available online: http://www.incadevice.com. Accessed May 6, 2020.

102. Respiro Sense, Diskus, Ellipta, Handihaler, Nexthaler, Turbospin. Available online: https://amiko.io. Accessed May 6, 2020.

103. Inspair. Available online: https://biocorpsys.com/en/nosproduits/dispositifs-connectes/inspair/. Accessed May 6, 2002.

104. Pneumahaler. Available online: http://pneumarespiratory. com. Accessed May 5, 2020.

105.ProAir Digihaler. Available online: https://www. proairdigihaler.com. Accessed May 5, 2020.

106. Greene G, Costello RW. Personalizing medicine - could the smart inhaler revolutionize treatment for COPD and asthma patients? Expert Opin Drug Deliv 2019;16:675-7.

107. Mokoka MC, McDonnell MJ, MacHale E, et al. Inadequate assessment of adherence to maintenance medication leads to loss of power and increased costs in trials of severe asthma therapy: results from a systematic literature review and modelling study. Eur Respir J 2019;53:1802161.

108.Zijp TR, Mol PGM, Touw DJ, et al. Smart medication adherence monitoring in clinical drug trials: a prerequisite for personalised medicine? EClinicalMedicine 2019;15:3-4.

109. Foster JM, Usherwood T, Smith L, et al. Inhaler reminders improve adherence with controller treatment in primary care patients with asthma. J Allergy Clin Immunol 2014;134:1260-1268.e3.

110. O'Dwyer S, Greene G, MacHale E, et al. Personalized biofeedback on inhaler adherence and technique by community pharmacists: a cluster randomized clinical trial. J Allergy Clin Immunol Pract 2020;8:635-44.

111. Sulaiman I, Greene G, MacHale E, et al. A randomised clinical trial of feedback on inhaler adherence and technique in patients with severe uncontrolled asthma. Eur Respir J 2018;51:1701126.

112. Morton RW, Elphick HE, Rigby AS, et al. STAAR: A randomised controlled trial of electronic adherence monitoring with reminder alarms and feedback to improve clinical outcomes for children with asthma. Thorax 2017;72:347-54.

113. Vasbinder EC, Goossens LMA, Rutten-Van Mölken MPMH, et al. E-Monitoring of asthma therapy to improve compliance in children (e-MATIC): A randomised controlled trial. Eur Respir J 2016;48:758-67.

114. Merchant RK, Inamdar R, Quade RC. Effectiveness of population health management using the propeller health asthma platform: a randomized clinical trial. J Allergy Clin Immunol Pract 2016;4:455-63.

115.Apter AJ, Wang X, Bogen DK, et al. Problem solving to improve adherence and asthma outcomes in urban adults with moderate or severe asthma: a randomized controlled trial. J Allergy Clin Immunol 2011;128:516-23.e1-5.

116. Charles T, Quinn D, Weatherall M, et al. An audiovisual reminder function improves adherence with inhaled corticosteroid therapy in asthma. J Allergy Clin Immunol 2007;119:811-6.

117. Onyirimba F, Apter A, Reisine S, et al. Direct clinician-topatient feedback discussion of inhaled steroid use: Its effect on adherence. Ann Allergy Asthma Immunol 2003;90:411-5.

118. Foster JM, Reddel HK, Usherwood T, et al. Patientperceived acceptability and behaviour change benefits of inhaler reminders and adherence feedback: A qualitative study. Respir Med 2017;129:39-45.

119. Howard S, Lang A, Sharples S, et al. See I told you I was taking it! - Attitudes of adolescents with asthma towards a device monitoring their inhaler use: Implications for future design. Appl Ergon 2017;58:224-37.

120. Chan AHY, Stewart AW, Harrison J, et al. Electronic adherence monitoring device performance and patient acceptability: a randomized control trial. Expert Rev Med Devices 2017;14:401-11.

121. Foster JM, Smith L, Usherwood T, et al. The reliability and patient acceptability of the smarttrack device: A new electronic monitor and reminder device for metered dose inhalers. J Asthma 2012;49:657-62.

122.van Boven JF, Tommelein E, Boussery K, et al. Improving inhaler adherence in patients with chronic obstructive pulmonary disease: a cost-effectiveness analysis. Respir Res 2014;15:66.

123. Gamble J, Stevenson M, Heaney LG. A study of a multilevel intervention to improve non-adherence in difficult to control asthma. Respir Med 2011;105:1308-15.

124.Zafari Z, Lynd LD, Fitzgerald JM, et al. Economic and health effect of full adherence to controller therapy in adults with uncontrolled asthma: a simulation study. J Allergy Clin Immunol 2014;134:908-915.e3.

125.van Boven JFM, Cushen B, Sulaiman I, et al. Personalising adherence-enhancing interventions using a smart inhaler in patients with COPD: an exploratory cost-effectiveness analysis. NPJ Prim Care Respir Med 2018;28:24.

126. Mokoka MC, Lombard L, MacHale EM, et al. In patients with severe uncontrolled asthma, does knowledge of adherence and inhaler technique using electronic 
monitoring improve clinical decision making? A protocol for a randomised controlled trial. BMJ Open 2017;7:e015367.

127. Pavord ID, Brightling CE, Woltmann G, et al. Noneosinophilic corticosteroid unresponsive asthma. Lancet 1999;353:2213-4.

128. McGrath KW, Icitovic N, Boushey HA, et al. A large subgroup of mild-to-moderate asthma is persistently noneosinophilic. Am J Respir Crit Care Med 2012;185:612-9.

129.Patel M, Pilcher J, Travers J, et al. Use of metered-dose inhaler electronic monitoring in a real-world asthma randomized controlled trial. J Allergy Clin Immunol Pract 2013;1:83-91.

130.Attaway AH, Alshabani K, Bender B, et al. The utility of electronic inhaler monitoring in COPD management. Chest 2020;157:1466-77.

131.van Boven JF, Trappenburg JC, van der Molen T, et al. Towards tailored and targeted adherence assessment to optimise asthma management. NPJ Prim Care Respir Med 2015;25:15046.

Cite this article as: Jansen EM, van de Hei SJ, Dierick BJH, Kerstjens HAM, Kocks JWH, van Boven JFM. Global burden of medication non-adherence in chronic obstructive pulmonary disease (COPD) and asthma: a narrative review of the clinical and economic case for smart inhalers. J Thorac Dis 2021;13(6):3846-3864. doi: 10.21037/jtd-20-2360
132. d'Ancona G, Kavanagh J, Roxas C, et al. Adherence to corticosteroids and clinical outcomes in mepolizumab therapy for severe asthma. Eur Respir J 2020;55:1902259.

133.van der Schans S, Goossens LMA, Boland MRS, et al. Systematic review and quality appraisal of costeffectiveness analyses of pharmacologic maintenance treatment for chronic obstructive pulmonary disease: methodological considerations and recommendations. Pharmacoeconomics 2017;35:43-63.

134. Sá-Sousa A, Almeida R, Vicente R, et al. High oral corticosteroid exposure and overuse of short-acting beta2-agonists were associated with insufficient prescribing of controller medication: a nationwide electronic prescribing and dispensing database analysis. Clin Transl Allergy 2019;9:47.

135.van Boven JF, Vegter S, van der Molen T, et al. COPD in the working age population: the economic impact on both patients and government. COPD 2013;10:629-39.

136. Cruz AA, Souza-Machado A, Franco R, et al. The impact of a program for control of asthma in a low-income setting. World Allergy Organ J 2010;3:167-74. 